\title{
Antibacterial, Antiviral, Antioxidant, and Anticancer Activities of Postbiotics: A review of Mechanisms and Therapeutic Perspectives
}

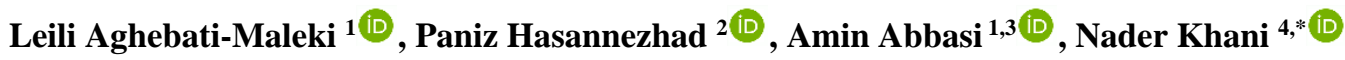 \\ Immunology Research Center, Tabriz University of Medical Sciences, Tabriz, Iran \\ Department of Medical Engineering Science, University College of Rouzbahan, Sari, Iran \\ Department of Food Science and Technology, Faculty of Nutrition \& Food Sciences, Tabriz University of Medical \\ Sciences, Tabriz, Iran \\ 4 Student Research Committee, Tabriz University of Medical Sciences, Tabriz, Iran \\ * Correspondence: naderxani1996m@gmail.com;
}

Scopus Author ID 57215873145

Received: 12.04.2021; Revised: 28.05.2021; Accepted: 1.06.2021; Published: 24.06.2021

\begin{abstract}
Several scientific evidence has shown the advantageous effects of probiotic-derived metabolites on human health. Postbiotics are a wide range of bioactive compounds derived from probiotics through a fermentation process and/or produced in pure forms in laboratory scales. These compounds have native biological activities that have been extensively studied in recent years. Immunomodulation, antimicrobial, anti-cancer, antioxidant, anti-diabetic, and reduction of food allergies compose the most important biological roles of postbiotics. In terms of safety, it has been confirmed that postbiotics, as potential substitute elements, might be superior to their parent live cells. Also, due to their appropriate economic, technological, and clinical features, they could be employed as favorable apparatuses in the food and drug industry to improve health benefits. This review comprehensively discusses the concept of postbiotics and their characteristics, emphasizing their potential antibacterial, antiviral, antioxidant, and anticancer activities.
\end{abstract}

Keywords: postbiotic; probiotic; antimicrobial; antiviral; antioxidant; anticancer.

(C) 2021 by the authors. This article is an open-access article distributed under the terms and conditions of the Creative Commons Attribution (CC BY) license (https://creativecommons.org/licenses/by/4.0/).

\section{Introduction}

The use of beneficial microorganisms in the food and pharmaceutical industries has a long history. According to a definition, probiotics are a group of living microorganisms in the mammalian intestines, which, when taken in sufficient quantities, play a positive role in improving human health [1]. Beneficial intestinal bacteria mainly include Bacteroides, Fusobacterium, Eubacteria, Peptococcus, Peptostreptococcus, Bifidobacterium, Escherichia, and Lactobacillus [2]. Interestingly, their useful effects have been shown, which include reducing lactose intolerance, preventing cancers, lowering blood cholesterol and absorbing it from the intestine (by breaking down bile in the intestine), lowering blood pressure, strengthening the immune system and preventing infections, preventing and treating acute diarrhea, decreasing intestinal inflammation, reducing food allergies or eczema in children, enhancing vitamin and mineral absorption, improving symptoms of irritable bowel syndrome and colitis, preventing the growth and proliferation of invading bacteria, improving gastrointestinal function and nutrient uptake, and assisting the production of $\mathrm{B}$ and $\mathrm{K}$ vitamins $[3,4]$. The beneficial effects of probiotics are exerted in the body through food supplements 
and/or pharmaceutical products .Due to these favorable effects, probiotics have found special applications in recent years [5]. For example, probiotics' antimicrobial, antioxidant, and anticancer effects have been widely used in laboratory, animal, and clinical models. Moreover, the antimicrobial effect of probiotics has been widely taken advantage of in the food industry [6,7]. Probiotics inhibit the growth of spoilage bacteria and pathogens during food storage, thus being an important way to preserve food and prevent the transmission of pathogens through food. Probiotics also have very strong antioxidant properties that prevent food oxidation during food storage [8,9]. Probiotics have been used extensively as anticancer compounds in laboratory, animal, and clinical models in recent years. Many studies have been conducted on the anticancer effects of probiotics [10]. Despite the beneficial effects of probiotics, the use of these bacteria has recently been shown to have challenges. One of the challenges with using probiotics is their viability. Prescribing supplements containing live probiotic bacteria to people of different ages and physical conditions do not always show the same beneficial effects. These bacteria have adverse effects in people with weakened immune systems and can cause many clinical problems. These include people with Crohn's disease, pregnant women, the elderly, and infants [11]. Other important challenges of using probiotics are the emergence of antibiotic resistance and transmission potential. The genes that cause virulence and resistance to pathogens are located in the host intestine. There are also opportunistic pathogenic bacteria in the intestinal microbiome, the acquisition of antibiotic resistance in which could be associated with serious problems [12]. Researchers have come up with various solutions in recent years to solve these challenges, and have suggested that one of the most effective and practical approaches in this regard is the use of an inanimate form of bacteria (postbiotics) as substitutes for probiotics [13]. Postbiotics are called inanimate forms and metabolites of probiotic bacteria that have beneficial effects if taken in sufficient amounts. In this review, we comprehensively discuss the concept of postbiotics and their characteristics, with emphasis on their potential antibacterial, antiviral, antioxidant, and anticancer activities.

\section{Characteristics of Postbiotics}

There are various definitions of postbiotics. Postbiotics are well-known as compounds generated throughout the process of fermentation in probiotic bacteria. They could also be generated by feeding particular fiber molecules to probiotics. They leave waste that is generally termed as postbiotic [14]. The most important example of postbiotics is SCFA, which is produced by the fermentation of carbohydrates [15]. Many terms have been used to name nonliving forms of probiotics in recent years, including postbiotic, pseudoprobiotic, ghost probiotics, paraprobiotic, metabiotic, abiotic, cell-free supernatant, and Biogenic [16]. Among these, "postbiotic" is more commonly used. However, 'paraprobiotic' and 'pseudoprobiotic' have also been used in a number of studies [15]. Various components are obtained with the lysis of probiotic bacteria, which could include short-chain fatty acids, cell wall fragments, enzymes, exopolysaccharides, and cell-free supernatants. There are two methods for producing and obtaining postbiotic compounds. The first is the natural method (fermentation process), and the second is the laboratory method [17]. In general, postbiotics have shown all the beneficial effects of probiotics, including strengthening the immune system, hypersensitivity, and antibacterial, antiviral, antioxidant, antiobesity, anti-diabetes, antihypertensive, antiproliferation, anti mutation, and anticancer effects, all of which have been proven both in vitro and in vivo [18]. In experimental and preclinical studies, no adverse effects (such as inflammation) of postbiotics have been observed. Therefore, postbiotics can be a safe 
alternative to probiotics, owing to their known chemical structures, safe dose, and longer shelf life [19]. Therefore, the safety of postbiotics is a good reason to apply them in the food and pharmaceutical industries. Several experiments have been conducted on the advantageous effects of postbiotics [20]. Importantly, the beneficial effects of postbiotics depend on the type of probiotic used to extract the postbiotics and the type of postbiotics themselves. Here, we examine the antibacterial, antiviral, antioxidant, and anti-cancer effects of postbiotics, focusing on their mechanism of function.

\section{Antibacterial Effects of Postbiotics}

Inhibition of pathogenic bacteria and food spoilage is one of the beneficial effects of postbiotics. Today, due to the advantages of postbiotics over antibiotics and chemical preservatives, the use of these compounds against pathogenic bacteria and food spoilage is common. Antibacterial effects of postbiotics depend on (a) the type of probiotic from which the postbiotic is prepared, (b) the type of target bacterium (Gram-positives are more resistant to gram- negatives against postbiotic compounds), and (c) the concentration of postbiotics [21]. Several postbiotics could exert direct antimicrobial effects as they seal the intestinal barrier and bind competitively to receptors that are needed by pathogens. They thus change host gene expression or modulate the local environment [22]. In this regard, in an in vitro study, the effects of postbiotics derived from Lactobacillus plantarum were investigated. Results indicated positive effects of postbiotics as inhibitory factors capable of reducing the adhesion and invasive ability of Listeria monocytogenes [23]. Postbiotic administration of probiotic bacteria L. casei, L. acidophilus, and L. delbruckii in mice enhanced gut IgA levels in small and large intestine lamina propria. This reduced the severity of enteric infections induced via pathogens, including Escherichia coli or Salmonella enteritidis serovar Typhimurium [24]. Antibacterial activity has also been shown in the supernatants of cultures of Bifidobacterium and Lactobacillus recently. This could be observed in vitro by preventing the invasion of enteroinvasive E. coli strains into enterocytes. The cell supernatants could also exert local effects on the expression of protective genes, cell barrier, and intestinal environment, even though such antibacterial features might be caused by inhibiting the adhesion of pathogenic bacteria (as they compete for receptor sites) [25]. The short-chain fatty acids (acetate) produced by lactobacilli prevented the infectivity of E. coli O157: $H 7$ in a mouse model. Lactic acid produced by six strains of Lactobacillus (L. acidophilus IBB 801, L. amylovorus DCE 471, L. casei Shirota, L. johnsonii La1, L. plantarum ACA-DC 287, and L. rhamnosus GG) from Salmonella enterica serovar Typhimurium SL1344 blocks Caco 2/TC7 cells, including human enterocytes [26]. According to studies, it could be concluded that each of the postbiotic compounds with its mechanism can kill pathogenic bacteria.

\subsection{Antibacterial mechanism of postbiotics.}

As mentioned, the effect of postbiotics on bacteria depends on factors such as the type of postbiotic and the bacteria. Postbiotics are not generally effective or are less effective, against Gram-positives bacteria since the antibacterial postbiotics cannot permeate the outer membrane of Gram-negative bacteria. It was shown by Enan et al. that L. plantarum UG1 had a more potent antibacterial activity against Gram-positive bacteria in comparison with Grampositive microorganisms. Therefore, due to the resistance of gram-negative bacteria, pesticides should be extracted from probiotic bacteria with high antimicrobial properties [27]. Postbiotic 
compounds derived from probiotics each have a specific antibacterial mechanism. In the following, we examine the bacterial mechanism of each postbiotic compound.

\subsubsection{Organic acid-based postbiotics.}

Organic acid-based postbiotics are compounds appropriate as antimicrobial agents [28]. Organic acids are known as one of the key postbiotics. Citric acid, acetic acid, and tartaric acid are the most important acids produced by probiotic bacteria and have strong antibacterial effects. Lactic acid, acetic acid, tartaric acid, malic acid, and citric acid inhibit pathogens by significantly reducing $\mathrm{pH}$ value [29]. The inhibitory effect of lactic acids is related to their effect on bacterial cell membranes. The antibacterial mechanism of organic acids is mainly observed through lowering intracellular $\mathrm{pH}$ and reducing membrane integrity. [30]. The antimicrobial activity of organic acids can be linked in two ways [29].

\subsubsection{Bacteriocin-based postbiotics.}

Bacteriocins are peptides or proteins with antibacterial activity produced by various bacteria, such as Lactubacillus and bifidobacters [30]. Bacteriocins have a high antibacterial activity that has been used for thousands of years by humans in producing fermented foods. Bacteriocins are classified based on size, mechanism of action, and inhibitory spectrum. Bacteriocins have many positive effects, such as inhibiting the growth and development of pathogenic bacteria, and are also heat-resistant and $\mathrm{pH}$-resistant [31]. The antibacterial mechanism of bacteriocins is mainly observed through their effect on bacterial cytoplasmic membranes. Bacteriocins are linked by affecting sensitive components, such as bacterial peptides, and inhibiting spore growth and pore formation in the cell membrane of pathogenic bacteria [32].

\subsubsection{Fatty acid-based postbiotics.}

Fatty acid-based postbiotics can be used as suitable alternatives to antibiotics due to their high antibacterial activity. In recent years, using short-chain fatty acids (FACs) produced by probiotic bacteria has become very common. FACs are formed from a saturated and an unsaturated carbon chain attached to a carboxylic (hydrophilic) group. Among fatty acids, lauric and meristic acids are highly active against bacterial growth and development [33]. Antibacterial mechanisms of FACs on bacteria include increasing membrane permeability (and leading to cell lysis), disrupting the electron transport chain, disrupting the structure and activity of enzymes, and morphological/functional changes on sensitive components such as proteins [34].

\subsubsection{Peptide-based postbiotics.}

Microorganisms produce antibacterial peptides. Peptide-based postbiotics destroy microbes through pleiotropic (multiple actions) mechanisms, such as microbial membrane degradation and inhibition of macromolecule synthesis [35]. Antibacterial peptides are divided into ribosomal and non-ribosomal types. Peptides produced by the bacteria are ribosomal [36], which show strong antibacterial activity in vitro by disrupting microbial membranes [37]. Peptides are commonly present in all bacteria. As mentioned earlier, the main target of some peptides is the cell membrane, while that of other peptides is the cytoplasm and disruption of metabolic accumulation of the nucleus [38]. The antibacterial mechanisms of peptides include 
creating physical holes that leak cellular content, damaging sensitive intracellular components of the microbes, activating lethal processes such as inducing hydrolases that have detrimental effects on the cell wall, and creating acidity in the bacterial cell membrane [39] (Figure 1).

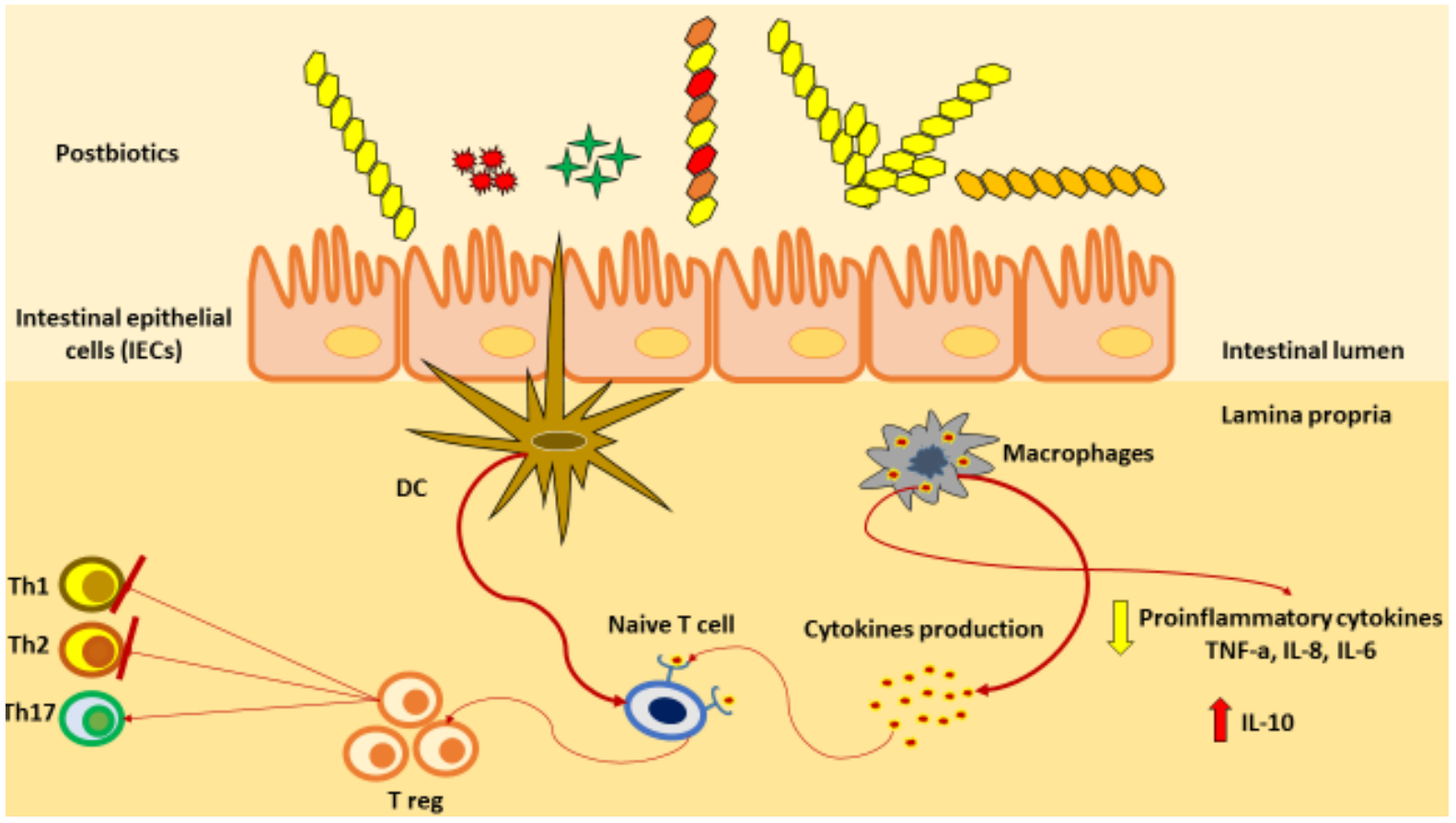

Figure 1. Antibacterial, antiviral, antioxidant, and anticancer activities of postbiotics. The postbiotics could induce activation and differentiation of DC, leading to CK production, subsequently, it mediated differentiation of naïve T cells into Tregs, which would control the excessive T cell response. Further, postbiotics could effectively stimulate the production of cytokines by macrophages which might induce homeostasis via reduction of pro-inflammatory CKs. Treg, regulatory T cell; DCs, dendritic cells; IL, interleukin; TH, T helper; TNF- $\alpha$, tumor necrosis factor-alpha.

\section{Antiviral Effect of Postbiotics}

Through threatening public health, emerging viral infections are considered global issues. It has was shown in vitro that postbiotics exert antiviral effects when encountering enveloped viruses. We now know well that to eliminate viruses successfully, the infected cell needs to induce a pro-inflammatory immune response and develop Th1-type immunity, both of which lead to the restriction of viral replication. Such responses depend on the production of inflammatory chemokines, cytokines, and interleukins, such as TNF- $\alpha$, interferons, IL-23, IL-18, and IL12, and cytotoxic activation of T-lymphocytes, NK cells, and monocytes/macrophages [40]. Probiotics and metabolites derived from them can protect against viral infections by enhancing adaptive and innate immunity. This reduces illness duration, shedding of the virus, and the number of episodes. It also enhances the generation of virus-specific antibodies and normalizes gut permeability [41]. Postbiotics can interfere with virus absorption and penetration into the host cell and inhibit several retroviral reverse transcriptases. The antiviral effect of postbiotics depends on the type of probiotic used to extract the postbiotics and the type of viruses. Many studies have been performed on the antiviral effect of probiotic metabolites (postbiotics). In a study, Firoz Anwar et al. (2020) showed the effect of plant-derived probiotics (Plantaricin) on SARS-CoV-2. It was observed that Plantaricin can prevent infection by modulating the immune system (by affecting $\mathrm{T}$ cells, producing IFN- $\gamma$, and reducing pre-inflammatory cytokines) and having a direct effect on the virus. SARS-CoV-2 enters the host cell via spike glycoprotein $(\mathrm{S})$ with a high affinity for the 
angiotensin-converting enzyme (ACE2) receptor. Once this glycoprotein enters the body with the enzyme angiotensin 2 converter (ACE2), it causes an infection in the body. Postbiotic (Plantaricin) compounds can inhibit Covid-19 pathogenicity by binding to spike glycoprotein (S) [42]. In another study, they examined the effect of cell-free metabolites of L. rhamnosus on enterovirus and Coxsackievirus in the HeLa, Vero, and Hep-2 cell lines. It was found that the metabolites of L. rhamnosus prevented viruses from attaching to cell lines [43]. In another study, B.J. Seo et al. (2012) examined the effect of Leuconostoc mesenteroides free cell supernatant on H9N2 in SPF chicks and found that the intake of probiotic metabolites significantly increased IFN-c cytokine production and made broilers immune against H9N2[44].

\subsection{Antiviral mechanism of postbiotics.}

The antiviral role of postbiotics is largely seen by preventing the virus from attaching to the host cell, which prevents the early stages of viral infection. The virus is prevented from entering the host cell by blocking viral binding to the host cell receptors [45]. Another mechanism involves strengthening the immune system by postbiotics. In addition, intracellular mechanisms have been predicted by other authors, suggesting that probiotics may interfere with the stages of the viral cycle within cells [46]. Postbiotic compounds have specific antiviral mechanisms. Here we examine the antiviral mechanism of postbiotics.

\subsubsection{Organic acid-based postbiotics.}

Organic acids produced by probiotic bacteria are known as postbiotic compounds, which could be introduced as antiviral agents [47]. Lactic acid is one of the most important organic acids produced by probiotics which enjoys antiviral activity [48]. Lactic acid is present in two isomers, including $\mathrm{L}$ and $\mathrm{D}$. The $\mathrm{L}$-shape is more effective in preventing viral infections. Citric acid and acetic acid also prevent the infection of viruses by creating an acidic environment. The antiviral mechanism of organic acids produced by probiotic bacteria is observed through the binding of organic acids to the glycoprotein (S) of viruses, thereby preventing viruses from binding to the angiotensin-converting enzyme (ACE2) [49].

\subsubsection{Fatty acid-based postbiotics.}

Among the most important metabolites of probiotic bacteria are fatty acids. Fatty acids from probiotic bacteria are known as postbiotic compounds. Like other postbiotic compounds, these compounds exert many beneficial effects (such as antiviral properties). The antiviral effect of fatty acids is due to their special structures. Fatty acids are formed from a saturated and an unsaturated carbon chain attached to a carboxylic (hydrophilic) group [47,50]. Fatty acids are also recognized as potential postbiotics with considerable antiviral properties. Lauric and meristic acids are highly active against the virus growth and development [33]. Fatty acids produced by probiotics, such as organic acids, bind to spike glycoprotein (S) and prevent it from binding to the angiotensin-converting enzyme 2 (ACE2).

\subsubsection{Peptide-based postbiotics.}

Antimicrobial peptides are $~ 12-50$ amino acid-long small proteins. Peptide compounds produced by probiotic bacteria exert potent antiviral effects. The use of peptide compounds against viruses is a very effective method. Studies have shown that peptide compounds 
produced by probiotic bacteria have excellent antiviral properties. In one study, the effect of peptides on influenza and Covid-19 viruses was assessed, where it was found that peptides prevented the proliferation of these viruses by inhibiting endosomal acidification [51].

\subsubsection{Hydrogen peroxide-based postbiotics.}

Hydrogen peroxide is mainly produced by all bacteria but is generally visible in aerobic cultures of catalase-negative bacteria and is the major metabolite of lactic acid bacteria [28]. Hydrogen peroxide produced by probiotics is known as a postbiotic [52]. These compounds have excellent antiviral properties. These compounds can disinfect materials because of interacting with vital constituents of bacteria, fungi, and viruses, including enzymes and nucleic acids (DNA, and RNA), thus preventing their replication and capacity of infection [53]. Therefore, the use of hydrogen peroxide from probiotic bacteria as an inhibitory compound of a virus is a good way to control viral infections.

\section{The Antioxidant Effect of Postbiotics}

Postbiotics enjoy particular mechanisms of defense effective in decreasing destructive effects of reactive oxygen species (ROS), which could potentially impair nucleic acids, carbohydrates, proteins, and lipids. Particularly, antioxidant enzymes, including catalase, peroxide dismutase (SOD), and glutathione peroxidase (GPx), possess significant parts in fighting against reactive oxygen species [54].

Tale 1. The following table shows the antioxidant application of postbiotics.

\begin{tabular}{|c|c|c|c|c|c|}
\hline $\begin{array}{l}\text { Probiotic } \\
\text { strain }\end{array}$ & Type of postbiotic & Type of assessment & Method & Antioxidant effect & References \\
\hline $\begin{array}{c}\text { Lactobacillus } \\
\text { plantarum } \\
\text { RG14 ، } \\
\text { RG11 }\end{array}$ & Enzyme & $\begin{array}{l}\text { As an oral supplement } \\
\text { for lambs }\end{array}$ & $\begin{array}{l}\text { 2,2-diphenyl-1-picryl- } \\
\text { hydrazyl (DPPH) }\end{array}$ & $\begin{array}{l}\text { Postbiotics increase the } \\
\text { antioxidant activity of } \\
\text { glutathione peroxidase } \\
\text { (GPX) in serum and } \\
\text { rumen fluid and GPX1, } \\
\text { GPX4, hepatic } \\
\text { superoxide dismutase }\end{array}$ & [58] \\
\hline $\begin{array}{l}\text { Lactobacillus } \\
\text { plantarum }\end{array}$ & Enzyme & $\begin{array}{l}\text { As an oral supplement } \\
\text { for broilers }\end{array}$ & $\begin{array}{l}\text { By examining meat } \\
\text { quality (pH, WHC, color } \\
\text { and sensitivity) }\end{array}$ & $\begin{array}{l}\text { Enhance the activity of } \\
\text { antioxidant enzymes. }\end{array}$ & [59] \\
\hline $\begin{array}{c}\text { Lactobacillus } \\
\text { plantarum } \\
\text { RI11 }\end{array}$ & Enzyme & $\begin{array}{l}\text { As an oral supplement } \\
\text { for broilers }\end{array}$ & $\begin{array}{l}\text { By checking the quality } \\
\text { of chicken meat }\end{array}$ & $\begin{array}{l}\text { Postbiotic increases the } \\
\text { activity of antioxidant } \\
\text { enzymes (GPx, CAT and } \\
\text { GSH) and decreases heat } \\
\text { stress marker }\end{array}$ & {$[24]$} \\
\hline $\begin{array}{l}\text { L. plantarum } \\
\text { RG11, } \\
\text { RG14, RI11, } \\
\text { RS5, TL1, } \\
\text { and UL4 }\end{array}$ & Organic acid & In vitro & $\begin{array}{c}\text { Hydroxyl Radical } \\
\text { Scavenging Assay (HRS) }\end{array}$ & $\begin{array}{l}\text { The HRS activity was } \\
\text { significantly higher }(\mathrm{P}< \\
0.05) \text { for the postbiotics } \\
\text { produced by the } \\
\text { formulated media as } \\
\text { compared to the control } \\
\text { MRS medium, even } \\
\text { though there was no } \\
\text { significant difference } \\
\text { among all the producer } \\
\text { strains }\end{array}$ & [60] \\
\hline
\end{tabular}

The above-mentioned azimuths obtained from probiotic bacteria are each known as postbiotic. In recent years, many studies have been conducted on the antioxidant effects of postbiotics (Table 1). Studies have shown favorable antioxidant effects for these enzymes. High GPx content has been reported in two strains of L. fermentum, which also enjoy significant antioxidant features in vitro [55]. L. plantarum-derived postbiotics were assessed 
for their antioxidant features by Izuddin et al., where the effect could be witnessed due to enhanced concentration of glutathione peroxidase in serum $(\mathrm{p}<0.05)$. Furthermore, superior relief of the symptoms of Crohn's disease in mice was demonstrated for genetically modified Lactobacillus strains capable of synthesizing catalase or SOD, as compared to their unmodified counterparts [56]. Additionally, Lactobacillus strains possessing improved activity of catalase showed more successful relief of inflammation in mice with inflammatory bowel disease, as compared to strains of the same bacterium which produced SOD (compared to controls, however, both strains reduced body temperature $(\mathrm{p}<0.05))$ [57]. It was shown in this trial that anti-inflammatory features of Lactobacillus strains depend on the profile of the expression of anti-oxidative enzymes for each strain. Moreover, genetically modified Lactobacillus lactis, which expressed catalase was capable of preventing chemically-induced colon cancer in mice [57]. To better understand the antioxidant effect of postbiotics, we here examine the antioxidant effect of enzymes produced by probiotics, each of which is known as a postbiotic compound.5.1. Antioxidant mechanism of postbiotics.

Studies on the antioxidant effect of metabolites have shown that the antioxidant effect of these compounds depends mostly on the type of probiotics selected to extract antioxidant enzymes. For example, L. fermentum has been shown to produce the highest amount of antioxidant enzymes. Therefore, the type of probiotics should be considered to extract more antioxidant enzymes. Probiotic bacteria produce a large number of antioxidant enzymes [61]. Here we introduce the antioxidant mechanism of these enzymes.

\subsubsection{Catalase.}

Catalase, as an enzyme naturally found in probiotics and other living organisms, breaks down hydrogen peroxide $\left(\mathrm{H}_{2} \mathrm{O}_{2}\right)$ into oxygen and water [62] Catalase is considered a postbiotic since it is produced as a metabolite of probiotic bacteria [63]. In general, catalase is a Reductase oxidase enzyme as it suppresses ROS. It, therefore, acts as an antioxidant and protects the cell against oxidative stress through the inhibition of active oxygen species [64]. Catalase consists of four polypeptide chains, each containing more than 500 amino acids. It contains four porphyrins (iron) that allow it to react with oxygenated water. The appropriate $\mathrm{pH}$ for the activity of this enzyme is 4-11 [65]. Therefore, when using these enzymes as Postbiotics with antioxidant properties, the $\mathrm{pH}$ of the food should also be considered.

\subsubsection{Superoxide dismutase.}

As an enzyme, superoxide dismutase is capable of catalyzing and facilitating the radical decomposition of superoxide $\left(\mathrm{O}_{2}^{-}\right)$into ordinary oxygen $\left(\mathrm{O}_{2}\right)$ or hydrogen peroxide $\left(\mathrm{H}_{2} \mathrm{O}_{2}\right)$ molecules [59]. There are three superoxide dismutase isoforms in living organisms, which include cytosolic SOD1 (copper, zinc-SOD), mitochondrial SOD2 (Mn-SOD), and extracellular SOD3 (EC-SOD) [66], each of which plays a different role in maintaining healthy cells. For example, SOD1 protects cellular cytoplasm, SOD2 supports cellular mitochondria from free radical damage, and SOD3, as an antioxidant compound, plays an important role in creating immunity against inflammatory diseases. This enzyme protects tissues against the effects of oxidative stress with its antioxidant activity [67]. Superoxide dismutase is an essential enzyme in the antioxidant system of living organisms. Like other living organisms, probiotics possess this enzyme, which as a metabolite of probiotics, is a type of postbiotic that can be used as an antioxidant compound [27,68]. 


\subsubsection{Glutathione peroxidases.}

Glutathione peroxidases are a family of enzymes with peroxidase activity whose main biological role is to keep organisms safe from oxidative damage. Glutathione peroxidase neutralizes the effects of $\mathrm{H}_{2} \mathrm{O}_{2}$ [69]. Another key feature of glutathione peroxidase involves reducing peroxides to alcohol and hampering free radicals' formation because cellular lipid compounds are sensitive to free radicals and produce lipid peroxide by the reaction. Glutathione peroxidase has several isoenzymes that are encoded by different genes [70]. These isoenzymes are located in different parts of the cell and have different substrate properties. Glutathione peroxidase 1 is the most abundant isoenzyme found in the cytoplasm of almost all mammalian tissues and its preferred substrate is hydrogen peroxide [71]. Glutathione peroxidase 2 is an extracellular enzyme and is present in the intestinal lumen [72]. Glutathione peroxidase 3 is also extracellular and is abundant in plasma [73]. Glutathione peroxidase 4 is highly preferred to lipid hydroperoxides and is expressed in almost all mammalian cells but at deficient levels [74].

\section{Anticancer Effects of Postbiotics}

The anti-cancer effect of postbiotics is another favorable effect of these compounds. The anti-cancer effect of postbiotics depends on the type of probiotic chosen to extract the postbiotics, the type of postbiotic, and the type of target organ involved in cancer [75]. Many studies have been conducted on the anticancer effect of postbiotics in experimental and preclinical phases (Table 2). For example, a study has demonstrated the postbiotic role of Lactobacillus paracasei in cortical cancer. The anti-cancer mechanism of L. paracasei is associated with an inhibitory effect of cell wall protein on human cell carcinoma and cell growth [76]. Another study has examined the anticancer effect of postbiotics produced by Enterococcus on carcinogenic cells. This anticancer effect is linked to bacteriocins produced by probiotics, especially Enterocin, with the highest anticancer effect among bacteriocins. Similarly, the anticancer effect of L. plantarum I-UL4 on cancer cells was investigated, which showed the anticancer effect of bacteriocin produced. Bacteriocins have cytostatic and apoptotic effects against cancer cells [77].

Table 2. Potential anticancer activity of postbiotics.

\begin{tabular}{|c|c|c|c|c|c|}
\hline Probiotic strain & $\begin{array}{c}\text { Type of } \\
\text { postbiotic }\end{array}$ & Cancer cell line & Effect (s) & $\begin{array}{c}\text { Method of evaluating } \\
\text { anticancer activity }\end{array}$ & References \\
\hline $\begin{array}{l}\text { Lactobacillus } \\
\text { plantarum }\end{array}$ & Bacteriocin & $\begin{array}{l}\text { Human breast cancer } \\
\text { cells MCF-7 }\end{array}$ & $\begin{array}{l}\text { Decreased cell } \\
\text { proliferation }\end{array}$ & $\begin{array}{l}\text { Observation of the cytotoxic } \\
\text { effect of postbiotics by } \\
\text { fluorescent microscopic } \\
\text { observation using AO / PI color } \\
\text { reagents and flow cytometric } \\
\text { analyzes } \\
\end{array}$ & [78] \\
\hline $\begin{array}{l}\text { Lactobacillus } \\
\text { plantarum I-UL4 }\end{array}$ & Protein & $\begin{array}{l}\text { MCF-7 breast cancer } \\
\text { cell }\end{array}$ & $\begin{array}{l}\text { Cytotoxicity and } \\
\text { decreased } \\
\text { proliferation }\end{array}$ & $\begin{array}{c}\text { Via 3- (4, } 5 \text { dimethylthiazol-2- } \\
\text { yl) -2, 5-diphenyl Tetrazolium } \\
\text { Bromide and Trypan Blue Dye } \\
\text { Deprivation Method. }\end{array}$ & [79] \\
\hline $\begin{array}{l}\text { Lactobacillus } \\
\text { casei } \text { and } \\
\text { Lactobacillus } \\
\text { paracasei } \\
\end{array}$ & Protein & Cervical cancer cells & $\begin{array}{l}\text { Reduce apoptosis, } \\
\text { bind to carcinogenic } \\
\text { genotoxins and } \\
\text { reduce proliferation } \\
\end{array}$ & $\begin{array}{l}\text { Via RT-q PCR and western } \\
\text { blotting }\end{array}$ & {$[80]$} \\
\hline $\begin{array}{l}\text { Lactobacillus } \\
\text { paracasei } \mathrm{K} 5\end{array}$ & Protein & $\begin{array}{l}\text { Human colon cancer } \\
\text { cells }\end{array}$ & $\begin{array}{l}\text { Anti-proliferative } \\
\text { activity and apoptotic } \\
\text { effects }\end{array}$ & $\begin{array}{l}\text { Employing quantitative analysis } \\
\text { and confocal, fluorescent } \\
\text { microscopy the adhesion } \\
\text { properties of the postbiotics } \\
\text { were studied }\end{array}$ & {$[81]$} \\
\hline
\end{tabular}


In general, several molecular mechanisms compose in the anticancer activity of postbiotics, including diminution of the viability of the cell, regulation of immune response, control of carcinogenic and mutagenic agents, activation of the apoptotic cell death pathway, inhibition of gut dysbiosis, an increase of necrosis and apoptosis rate in cancer cells [18].

\subsection{Anticancer mechanism of postbiotics.}

Recently, many in vitro and in vivo investigations have shown that postbiotics possess an essential part in preventing and treating cancers of various body organs. Several molecular mechanisms with roles in the function of postbiotics were demonstrated in those studies, including regulation of immune responses, increasing apoptosis and necrosis, inhibition of carcinogenic and mutagenic factors, reducing bacterial transmission, activation of proapoptotic cell death pathways, and increasing tumor cell death through Autophagy [82]. Mechanism of bacterial carcinogenesis is observed by producing various toxins that disrupt the modification of the cell cycle, proliferation, differentiation, and apoptosis [83].

\subsubsection{Reduction of bacterial transmission.}

Different bacteria are involved in causing cancer. Colorectal cancer is a common disease caused by pathogenic bacteria (Streptococcus bovis, Enterococcus spp., Helicobacter pylori and E. coli) [84]. Also, gastric cancer is often caused by Helicobacter pylori. Bacteria and their associated products can participate in the formation of the disease by developing various mechanisms, such as the induction of pro-inflammatory and carcinogenic pathways in epithelial cells, the generation of genotoxins and ROS, and the transformation of precancerous dietary agents [85]. Due to their antibacterial effects, postbiotic compounds can prevent bacteria from attaching to the intestinal epithelium and producing toxins and can prevent these bacteria from causing cancer.

\subsubsection{Inhibition of mutagenic and carcinogenic factors.}

Postbiotics may kill active carcinogenic components or exert effects on the function of cancer-stimulating/inactivating enzymes. Some in vitro experiments have shown that the antimutagenic property of probiotics could be attributed to the postbiotics derived from it, including secretory glycoproteins, polysaccharides, and peptide glycans, as well as to the phase of bacterial growth, ambient $\mathrm{pH}$, mutant type, and related strain [78]. Probiotics and postbiotics derived from them can also bind to mutagenic agents, leading to biological deformation and consequent detoxification. Molecular mechanisms with significant parts in anti-mutagenic features of postbiotics include mutagen-binding, stimulation of chemopreventive enzymes, inhibition of enzymes that activate carcinogens, and inhibition of DNA damage [86]. Therefore, it could be proposed that postbiotics might be capable of exhibiting anti-mutagenic and anti-oxidant activities via distinct mechanisms and could accordingly be regarded as effective prophylactic agents when combatting cancer [87].

\subsubsection{Activation of pro-apoptotic cell death pathways.}

Cancer cells possess unregulated proliferation and growth and are capable of fighting apoptotic responses. In damaged cells, most apoptosis responses and survival mechanisms are changed adversely. The process of apoptosis is described as a major method of abnormal cell death in cancer patients because of its exceptional features (normal host response, without 
inflammatory response) [88]. Metabolites produced by Lactobacillus spp. inactivate cells by affecting cell wall components, peptidoglycans, cytoplasmic extracts, and cell-free processes which could have anti-proliferative and apoptotic responses to cancer cells. In this regard, Lactobacillus spp derived metabolites have been shown to have an inhibitory effect with a rapid apoptotic response and cell cycle inhibition in the S phase in HT-29 cancer cell lines [89].

\subsubsection{Increased intestinal acidity.}

Postbiotic components, such as FACs and organic acids (propionate and lactate) fermented by the microbial colon, are produced from active carbohydrates such as prebiotics that can acidify the intestinal environment and prevent the growth of pathogens that are effective in cancerous tumor formation. Such acids possess significant parts in cancer suppression and might potentially exert systemic and local biological effects [82]. Among postbiotics, FACs enjoys an ideal energy resource for colonocytes which potentiates the differentiation of mucosal cell, contributes to epithelial barrier function, controls apoptosis, prevents the differentiation and growth of cells, and controls glutathione S-transferase and histone acetylation pattern [90].

\section{The Multifunctional Perspectives of Postbiotics}

Postbiotic compounds may have multiple functions [91] (Figure 2). Postbiotics with antioxidant properties (enzymes) can have anti-proliferative and pro-apoptotic effects on cancer cells. It was shown that some Bifidobacterium and Lactobacilli are capable of inducing enhanced activity of anti-oxidative enzymes or modulating circulatory oxidative stress protecting cells against damage induced by carcinogens [92]. Fatty acids produced by Lactobacillus can heal the gut by reducing pro-inflammatory cytokines. Fatty acids can also prevent E. coli O157: H7 enterohaemorrhagic infection [93]. Some EPS generated via Lactobacillus strains isolated from fermented Durian fruit enjoy antioxidant and antimicrobial features. The antioxidant feature of an EPS (uronic acid) derived from Lactobacillus helveticus was attributed to its capability for binding to iron ions, to which the antioxidant characteristics of green tea could also be attributed [17,94].

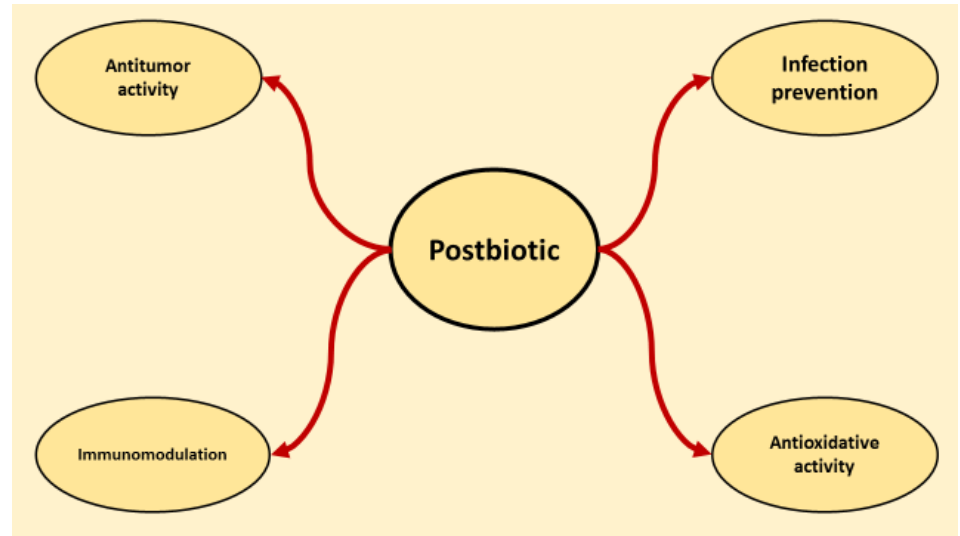

Figure 2. The multifunctional perspectives of postbiotics.

Exopolysaccharides are capable of interacting with Dectin-1 receptors and activating them on macrophage surfaces. Resultantly, $\beta$-glucans might improve cellular immune responses against bacteria, viruses, parasites, and cancer cells [95]. Abdelkarim Mahdhi et al. (2017) investigated the antibacterial and antioxidant effects of EPS from L. plantarum, in vitro. This study found that EPS produced by L. plantarum prevents the growth of this 
bacterium through oxidation of linoleic acid, lipid peroxidation, and biofilm formation by Staphylococcus aureus and Salmonella typhimurium [96,97]. Taken together, it could be concluded that each of the postbiotic compounds can have numerous functions. Despite the studies on several effects of postbiotics, the mechanism of action of multiple effects of postbiotics has not yet been determined. Therefore, it is necessary to conduct future studies to determine the mechanism of various effects of postbiotics.

\section{Conclusions}

Pathogenic microorganisms, carcinogenesis, and oxidative stress threaten public health. Many treatments are used to control the risks in this regard, which cost much money each year. Postbiotics, as metabolites or non-living forms of probiotics with many health effects. Postbiotics have been used in recent years for various purposes, including assessing their antimicrobial, anticancer, and antioxidant activities. Excellent results have been reported in this regard. Each postbiotic compound (proteins, fatty acids, peptides, bacteriocins, enzymes, organic acids, and hydrogen peroxide) has specific antimicrobial, antioxidant, and anticancer mechanisms. Postbiotics are achieved through the activity of probiotic bacteria (fermentation) or are produced on a laboratory scale. Previous research has shown that postbiotics have clinical (safety), technological (sustainability) and economical (low costs of production) advantages over probiotics. They are therefore safe alternatives to probiotics. Due to their unique properties, postbiotics can be used as promising tools to control pathogenic microorganisms, as well as a novel bio-preservative agent in the formulation of functional foods. Studies on the antimicrobial, antioxidant, and anticancer effects of postbiotics have been conducted extensively both in vivo and in vitro. Many metabolic and clinical studies are needed to arrive at new types of postbiotics, safe doses, and compound chemical structures.

\section{Funding}

This research received no external funding.

\section{Acknowledgments}

The research protocol was approved \& Supported by the Student Research Committee, Tabriz University of Medical Sciences (grant number 66555).

\section{Conflicts of Interest}

The authors declare that they have no conflicts of interest.

\section{References}

1. Shin, D.; Chang, S.Y.; Bogere, P.; Won, K.; Choi, J.-Y.; Choi, Y.-J.; Lee, H.K.; Hur, J.; Park, B.-Y.; Kim, Y.; Heo, J. Beneficial roles of probiotics on the modulation of gut microbiota and immune response in pigs. PloS one 2019, 14, e0220843, https://doi.org/10.1371/journal.pone.0220843.

2. Vasquez, E.C.; Pereira, T.; Peotta, V.A.; Baldo, M.P.; Campos-Toimil, M. Probiotics as beneficial dietary supplements to prevent and treat cardiovascular diseases: uncovering their impact on oxidative stress. Oxidative Medicine and Cellular Longevity 2019, https://doi.org/10.1155/2019/3086270.

3. Rad, AH.; Maleki, LA.; Kafil, HS.; Zavoshti, HF,; Abbasi, A. Postbiotics as novel health-promoting ingredients in functional foods. Health promotion perspectives 2020, https://doi.org/ 10.15171/hpp.2020.02.

4. Ansari, F.; Pourjafar, H.; Tabrizi, A.; Homayouni, A. The effects of probiotics and prebiotics on mental disorders: a review on depression, anxiety, Alzheimer, and autism spectrum disorders. Current Pharmaceutical Biotechnology 2020, https://doi.org/10.2174/1389201021666200107113812. 
5. Abbasi, A.; Aghebati-Maleki, A.; Yousefi, M.; Aghebati-Maleki, L. Probiotic intervention as a potential therapeutic for managing gestational disorders and improving pregnancy outcomes. Journal of reproductive immunology 2021, 143, 103244, https://doi.org/10.1016/j.jri.2020.103244.

6. Angelin, J.; Kavitha, M. Exopolysaccharides from probiotic bacteria and their health potential. International Journal of Biological Macromolecules 2020, https://doi.org/10.1016/j.ijbiomac.2020.06.190.

7. Ragul, K.; Kandasamy, S.; Devi, P.B.; Shetty, P.H. Evaluation of functional properties of potential probiotic isolates from fermented brine pickle. Food Chemistry 2020, 311, 126057, https://doi.org/10.1016/j.foodchem.2019.126057.

8. Chetwin, E.; Manhanzva, M.T.; Abrahams, A.G.; Froissart, R.; Gamieldien, H.; Jaspan, H.; Jaumdally, S.Z.; Barnabas, S.L.; Dabee, S.; Happel, A.-U. Antimicrobial and inflammatory properties of South African clinical Lactobacillus isolates and vaginal probiotics. Scientific reports 2019, 9, 1-15, https://doi.org/10.1038/s41598018-38253-4.

9. Barros, R.G.C.; Pereira, U.C.; Andrade, J.K.S.; de Oliveira, C.S.; Vasconcelos, S.V.; Narain, N. In vitro gastrointestinal digestion and probiotics fermentation impact on bioaccessbility of phenolics compounds and antioxidant capacity of some native and exotic fruit residues with potential anti-diabetic effects. Food Research International 2020, 136, 109614, https://doi.org/10.1016/j.foodres.2020.109614.

10. Vivarelli, S.; Falzone, L.; Basile, M.S.; Nicolosi, D.; Genovese, C.; Libra, M.; Salmeri, M. Benefits of using probiotics as adjuvants in anticancer therapy. World Academy of Sciences Journal 2019, 1, 125-135, https://doi.org/10.3892/wasj.2019.13.

11. Devirgiliis, C.; Zinno, P.; Perozzi, G. Update on antibiotic resistance in foodborne Lactobacillus and Lactococcus species. Frontiers in Microbiology 2013, 4, 301, https://doi.org/10.3389/fmicb.2013.00301.

12. Ogier, J.-C.; Serror, P. Safety assessment of dairy microorganisms: the Enterococcus genus. International journal of food microbiology 2008, 126, 291-301, https://doi.org/10.1016/j.ijfoodmicro.2007.08.017.

13. Mathur, S.; Singh, R. Antibiotic resistance in food lactic acid bacteria-a review. International journal of food microbiology 2005, 105, 281-295, https://doi.org/10.1016/j.ijfoodmicro.2005.03.008.

14. Homayouni Rad, A.; Aghebati Maleki, L.; Samadi Kafil, H.; Abbasi, A. Postbiotics: A novel strategy in food allergy treatment. Critical Reviews in Food Science and Nutrition 2020, 1-8, https://doi.org/10.1080/10408398.2020.1738333.

15. Yordshahi, A.S.; Moradi, M.; Tajik, H.; Molaei, R. Design and preparation of antimicrobial meat wrapping nanopaper with bacterial cellulose and postbiotics of lactic acid bacteria. International journal of food microbiology 2020, 321, 108561, https://doi.org/10.1016/j.ijfoodmicro.2020.108561.

16. Rad, A.H.; Aghebati-Maleki, L.; Kafil, H.S.; Abbasi, A. Molecular mechanisms of postbiotics in colorectal cancer prevention and treatment. Critical Reviews in Food Science and Nutrition 2020, 1-17, https://doi.org/10.1080/10408398.2020.1765310.

17. Bomfim, V.B.; Neto, J.H.P.L.; Leite, K.S.; de Andrade Vieira, É.; Iacomini, M.; Silva, C.M.; dos Santos, K.M.O.; Cardarelli, H.R. Partial characterization and antioxidant activity of exopolysaccharides produced by Lactobacillus plantarum CNPC003. LWT 2020, 109349, https://doi.org/10.1016/j.lwt.2020.109349.

18. Homayouni Rad, A.; Aghebati Maleki, L.; Samadi Kafil, H.; Fathi Zavoshti, H.; Abbasi, A. Postbiotics as Promising Tools for Cancer Adjuvant Therapy. Advanced Pharmaceutical Bulletin 2021, 11, https://doi.org/10.34172/apb.2021.007.

19. Moradi, M.; Molaei, R.; Guimarães, J.T. A review on preparation and chemical analysis of postbiotics from lactic acid bacteria. Enzyme and Microbial Technology 2020, 109722, https://doi.org/10.1016/j.enzmictec.2020.109722.

20. Nami, Y.; Abdullah, N.; Haghshenas, B.; Radiah, D.; Rosli, R.; Khosroushahi, A.Y. Assessment of probiotic potential and anticancer activity of newly isolated vaginal bacterium Lactobacillus plantarum 5BL. Microbiology and immunology 2014, 58, 492-502, https://doi.org/10.1111/1348-0421.12175.

21. Moradi, M.; Kousheh, S.A.; Almasi, H.; Alizadeh, A.; Guimarães, J.T.; Y1lmaz, N.; Lotfi, A. Postbiotics produced by lactic acid bacteria: The next frontier in food safety. Comprehensive Reviews in Food Science and Food Safety 2020, 19, 3390-3415, https://doi.org/10.1111/1541-4337.12613.

22. Nataraj, B.H.; Ali, S.A.; Behare, P.V.; Yadav, H. Postbiotics-parabiotics: the new horizons in microbial biotherapy and functional foods. Microbial cell factories 2020, 19, 1-22, https://doi.org/10.1186/s12934-02001426-w.

23. Moradi, M.; Mardani, K.; Tajik, H. Characterization and application of postbiotics of Lactobacillus spp. on Listeria monocytogenes in vitro and in food models. LWT 2019, 111, 457-464, https://doi.org/10.1016/j.lwt.2019.05.072.

24. Humam, A.M.; Loh, T.C.; Foo, H.L.; Izuddin, W.I.; Zulkifli, I.; Samsudin, A.A.; Mustapha, N.M. Supplementation of postbiotic RI11 improves antioxidant enzyme activity, upregulated gut barrier genes, and reduced cytokine, acute phase protein, and heat shock protein 70 gene expression levels in heat-stressed broilers. Poultry Science 2020, https://doi.org/10.1016/j.psj.2020.12.011.

25. Safari, M.S.; Keyhanfar, M.; Shafiei, R. Investigating the antibacterial effects of some Lactobacillus, Bifidobacterium and acetobacter strains killed by different methods on Streptococcus mutans and Escherichia coli. Molecular Biology Research Communications 2019, 8, 103, https://doi.org/10.22099/mbrc.2019.33582.1399. 
26. Bhat, M.I.; Sowmya, K.; Kapila, S.; Kapila, R. Potential Probiotic Lactobacillus rhamnosus (MTCC-5897) Inhibits Escherichia coli Impaired Intestinal Barrier Function by Modulating the Host Tight Junction Gene Response. Probiotics and Antimicrobial Proteins 2019, 1-12, https://doi.org/10.1007/s12602-019-09608-8.

27. Korotkyi, O.; Dvorshchenko, K.; Vovk, A.; Dranitsina, A.; Tymoshenko, M.; Kot, L.; Ostapchenko, L. Effect of probiotic composition on oxidative/antioxidant balance in blood of rats under experimental osteoarthritis. Ukr. Biochem. J 2019, 91, 49-58, https://doi.org/10.15407/ubj91.06.049.

28. Aljumaah, M.R.; Alkhulaifi, M.M.; Abudabos, A.M.; Alabdullatifb, A.; El-Mubarak, A.H.; Al Suliman, A.R.; Stanley, D. Organic acid blend supplementation increases butyrate and acetate production in Salmonella enterica serovar Typhimurium challenged broilers. Plos one 2020, 15, e0232831, https://doi.org/10.1371/journal.pone.0232831.

29. Mani-López, E.; García, H.; López-Malo, A. Organic acids as antimicrobials to control Salmonella in meat and poultry products. Food Research International 2012, 45, 713-721, https://doi.org/10.1016/j.foodres.2011.04.043.

30. Rad, AH.; Abbasi, A.; Kafil, HS.; Ganbarov, K. Potential pharmaceutical and food applications of postbiotics: $\begin{array}{lllll}\text { a } & \text { review. } & \text { Current } & \text { pharmaceutical }\end{array}$ https://doi.org/10.2174/1389201021666200516154833.

31. Gálvez, A.; Abriouel, H.; López, R.L.; Omar, N.B. Bacteriocin-based strategies for food biopreservation. $\begin{array}{llllll}\text { International journal of food microbiology } & \mathbf{2 0 0 7}, & \text { 120, }\end{array}$ https://doi.org/10.1016/j.ijfoodmicro.2007.06.001.

32. O’Connor, P.M.; Kuniyoshi, T.M.; Oliveira, R.P.; Hill, C.; Ross, R.P.; Cotter, P.D. Antimicrobials for food and feed; a bacteriocin perspective. Current Opinion in Biotechnology 2020, 61, 160-167, https://doi.org/10.1016/j.copbio.2019.12.023.

33. Mali, J.K.; Sutar, Y.B.; Pahelkar, A.R.; Verma, P.M.; Telvekar, V.N. Novel fatty acid-thiadiazole derivatives as potential antimycobacterial agents. Chemical Biology \& Drug Design 2020, 95, 174-181, https://doi.org/10.1111/cbdd.13634.

34. Yoon, B.K.; Jackman, J.A.; Valle-González, E.R.; Cho, N.-J. Antibacterial free fatty acids and monoglycerides: biological activities, experimental testing, and therapeutic applications. International journal of molecular sciences 2018, 19, 1114, https://doi.org/10.3390/ijms19041114.

35. Waghu, F.H.; Idicula-Thomas, S. Collection of antimicrobial peptides database and its derivatives: Applications and beyond. Protein Science 2020, 29, 36-42, https://doi.org/10.1002/pro.3714.

36. Rad, A.H.; Abbasi, A.; Javadi. A,; Pourjafar, H.; Javadi, M.; Khaleghi, M. Comparing the microbial quality of traditional and industrial yoghurts. Biointerface Research in Applied Chemistry 2020,10, 6020-5, https://doi.org/10.33263/BRIAC104.020025.

37. Hanson, M.A.; Dostalova, A.; Ceroni, C.; Poidevin, M.; Kondo, S.; Lemaitre, B. Synergy and remarkable specificity of antimicrobial peptides in vivo using a systematic knockout approach. Elife 2019, 8, e44341, https://doi.org/10.7554/eLife.44341.

38. Karimi, N.; Jabbari, V.; Nazemi, A.; Ganbarov, K.; Karimi, N.; Tanomand, A.; Karimi, S.; Abbasi, A.; Yousefi, B.; Khodadadi, E.; Kafil, H.S. Thymol, cardamom and Lactobacillus plantarum nanoparticles as a functional candy with high protection against Streptococcus mutans and tooth decay. Microbial pathogenesis 2020,148:104481, https://doi.org/10.1016/j.micpath.2020.104481.

39. Zasloff, M. Antimicrobial peptides of multicellular organisms. Nature 2002, 415, 389-395, https://doi.org/10.1038/415389a.

40. Alsaadi, L.G.; Baker, B.A.A.; Kadhem, B.M.; Mahdi, L.H.; Mater, H.N. Exopolysaccharide As Antiviral, Antimicrobial And As Immunostimulants: A Review. Plant archives 2020, 20, 5859-5875.

41. Wu, J.; Zhang, Y.; Ye, L.; Wang, C. The anti-cancer effects and mechanisms of lactic acid bacteria exopolysaccharides in vitro: A review. Carbohydrate Polymers 2020, 117308, https://doi.org/10.1016/j.carbpol.2020.117308.

42. Aguila, E.J.T.; Lontok, M.A.D.; Aguila, E.J.T. Letter: role of probiotics in the COVID-19 pandemic. Alimentary Pharmacology \& Therapeutics 2020, 52, 931, https://doi.org/10.1111/apt.15898.

43. Kalinichenko, S.V.; Melentyeva, K.V.; Manee, H.; Dubinina, N.V.; Zvereva, N.V.; Toryanik, I.I.; Popova, N.G.; Pakhomov, O.V. Study of anti-virus actions of metabolites of Lactobacteria. Wiadomosci Lekarskie 2020, 73, https://doi.org/10.36740/WLek2022007132.

44. Seo, B.; Rather, I.; Kumar, V.; Choi, U.; Moon, M.; Lim, J.; Park, Y. Evaluation of Leuconostoc mesenteroides YML003 as a probiotic against low-pathogenic avian influenza (H9N2) virus in chickens. Journal of applied microbiology 2012, 113, 163-171, https://doi.org/10.1111/j.1365-2672.2012.05326.x.

45. Baud, D.; Dimopoulou Agri, V.; Gibson, G.R.; Reid, G.; Giannoni, E. Using probiotics to flatten the curve of coronavirus disease COVID-2019 pandemic. Frontiers in public health 2020, 8, 186, https://doi.org/10.3389/fpubh.2020.00186.

46. Sundararaman, A.; Ray, M.; Ravindra, P.; Halami, P.M. Role of probiotics to combat viral infections with emphasis on COVID-19. Applied microbiology and biotechnology 2020, 1-16, https://doi.org/10.1007/s00253-020-10832-4. 
47. Churchward, C.P.; Alany, R.G.; Snyder, L.A. Alternative antimicrobials: the properties of fatty acids and monoglycerides. Critical reviews in microbiology 2018, 44, 561-570, https://doi.org/10.1080/1040841X.2018.1467875.

48. Li, Y.-L.; Ma, S.-C.; Yang, Y.-T.; Ye, S.-M.; But, P.P.-H. Antiviral activities of flavonoids and organic acid from Trollius chinensis Bunge. Journal of Ethnopharmacology 2002, 79, 365-368, https://doi.org/10.1016/s0378-8741(01)00410-X.

49. Gurung, A.B.; Ali, M.A.; Lee, J.; Farah, M.A.; Al-Anazi, K.M. Unravelling lead antiviral phytochemicals for the inhibition of SARS-CoV-2 Mpro enzyme through in silico approach. Life Sciences 2020, 117831, https://doi.org/10.1016/j.lfs.2020.117831.

50. Desbois, A.P. Potential applications of antimicrobial fatty acids in medicine, agriculture and other industries. Recent patents on anti-infective drug discovery 2012, 7, 111-122, https://doi.org/10.2174/157489112801619728.

51. Elnagdy, S.; AlKhazindar, M. The potential of antimicrobial peptides as an antiviral therapy against COVID19. ACS pharmacology \& translational science 2020, 3, 780-782, https://doi.org/10.1021/acsptsci.0c00059.

52. Marshall, M.V. Hydrogen Peroxide and Viruses. Available online: https://providers.perioprotect.com/wpcontent/uploads/2020/07/White-Paper-Peroxide-and-Viruses-200712.pdf.

53. Bidra, A.S.; Pelletier, J.S.; Westover, J.B.; Frank, S.; Brown, S.M.; Tessema, B. Comparison of in vitro inactivation of SARS CoV-2 with hydrogen peroxide and povidone-iodine oral antiseptic rinses. Journal of Prosthodontics 2020, 29, 599-603, https://doi.org/10.1111/jopr.13220.

54. Homayouni, Rad.A.; Samadi, Kafil.H.; Fathi, Zavoshti.H.; Shahbazi, N.; Abbasi, A. Therapeutically Effects of Functional Postbiotic Foods. Clinical Excellence 2020, 10,33-52, http://ce.mazums.ac.ir/article-1-532en.html.

55. Capcarova, M.; Weiss, J.; Hrncar, C.; Kolesarova, A.; Pal, G. Effect of Lactobacillus fermentum and Enterococcus faecium strains on internal milieu, antioxidant status and body weight of broiler chickens. Journal of animal physiology and animal nutrition 2010, 94, e215-e224, https://doi.org/10.1111/j.14390396.2010.01010.x.

56. Zhang, L.; Liu, C.; Li, D.; Zhao, Y.; Zhang, X.; Zeng, X.; Yang, Z.; Li, S. Antioxidant activity of an exopolysaccharide isolated from Lactobacillus plantarum C88. International Journal of Biological Macromolecules 2013, 54, 270-275, https://doi.org/10.1016/j.ijbiomac.2012.12.037.

57. Humam, A.M.; Loh, T.C.; Foo, H.L.; Samsudin, A.A.; Mustapha, N.M.; Zulkifli, I.; Izuddin, W.I. Effects of feeding different postbiotics produced by Lactobacillus plantarum on growth performance, carcass yield, intestinal morphology, gut microbiota composition, immune status, and growth gene expression in broilers under heat stress. Animals 2019, 9, 644, https://doi.org/10.3390/ani9090644.

58. Izuddin, W.I.; Humam, A.M.; Loh, T.C.; Foo, H.L.; Samsudin, A.A. Dietary postbiotic lactobacillus plantarum improves serum and ruminal antioxidant activity and upregulates hepatic antioxidant enzymes and ruminal barrier function in post-weaning lambs. Antioxidants 2020, 9, 250, https://doi.org/10.3390/antiox9030250.

59. Lin, X.; Xia, Y.; Yang, Y.; Wang, G.; Zhou, W.; Ai, L. Probiotic characteristics of Lactobacillus plantarum AR113 and its molecular mechanism of antioxidant. LWT 2020, 126, 109278, https://doi.org/10.1016/j.lwt.2020.109278.

60. Chang, H.M.; Foo, H.L.; Loh, T.C.; Lim, E.T.C.; Mutalib, N.E.A. Comparative Studies of Inhibitory and Antioxidant Activities, and Organic Acids Compositions of Postbiotics Produced by Probiotic Lactiplantibacillus plantarum Strains Isolated From Malaysian Foods. Frontiers in veterinary science 2020, 7, https://doi.org/10.3389/fvets.2020.602280.

61. Wegh, C.A.; Geerlings, S.Y.; Knol, J.; Roeselers, G.; Belzer, C. Postbiotics and their potential applications in early life nutrition and beyond. International journal of molecular sciences 2019, 20, 4673, https://doi.org/10.3390/ijms20194673.

62. He, Z.; Huang, X.; Wang, C.; Li, X.; Liu, Y.; Zhou, Z.; Wang, S.; Zhang, F.; Wang, Z.; Jacobson, O. A Catalase-Like Metal-Organic Framework Nanohybrid for O2-Evolving Synergistic Chemoradiotherapy. Angewandte Chemie 2019, 131, 8844-8848, https://doi.org/

63. Ragavan, M.L.; Patnaik, N.; Muniyasamy, R.; Roy, A.; Deo, L.; Das, N. Biochemical Characterization and Enzymatic profiling of Potential Probiotic Yeast Strains. Research Journal of Pharmacy and Technology 2019, 12, 3941-3944, https://doi.org/10.1002/anie.201902612.

64. Kleniewska, P.; Pawliczak, R. The influence of apocynin, lipoic acid and probiotics on antioxidant enzyme levels in the pulmonary tissues of obese asthmatic mice. Life sciences 2019, 234, 116780, https://doi.org/10.1016/j.1fs.2019.116780.

65. Yang, G.; Shen, K.; Yu, R.; Wu, Q.; Yan, Q.; Chen, W.; Ding, L.; Kumar, V.; Wen, C.; Peng, M. Probiotic (Bacillus cereus) enhanced growth of Pengze crucian carp concurrent with modulating the antioxidant defense response and exerting beneficial impacts on inflammatory response via Nrf2 activation. Aquaculture 2020, 529, 735691, https://doi.org/10.1016/j.aquaculture.2020.735691.

66. Saqib, M.; Bashir, S.; Li, H.; Wang, S.; Jin, Y. Lucigenin-Tris (2-carboxyethyl) phosphine chemiluminescence for selective and sensitive detection of TCEP, superoxide dismutase, Mercury (II), and dopamine. Analytical chemistry 2019, 91, 3070-3077, https://doi.org/10.1021/acs.analchem.8b05486. 
67. Banerjee, M.; Vats, P.; Kushwah, A.; Srivastava, N. Interaction of antioxidant gene variants and susceptibility to type 2 diabetes mellitus. British journal of biomedical science 2019, 76, 166-171, https://doi.org/10.1080/09674845.2019.1595869.

68. Hassaan, M.S.; El-Sayed, A.; Mohammady, E.Y.; Zaki, M.A.; Elkhyat, M.M.; Jarmołowicz, S.; El-Haroun, E.R. Eubiotic effect of a dietary potassium diformate (KDF) and probiotic (Lactobacillus acidophilus) on growth, hemato-biochemical indices, antioxidant status and intestinal functional topography of cultured Nile tilapia Oreochromis niloticus fed diet free fishmeal. Aquaculture 2020, 533, 736147, https://doi.org/10.1016/j.aquaculture.2020.736147.

69. Brigelius-Flohé, R.; Flohé, L. Regulatory phenomena in the glutathione peroxidase superfamily. Antioxidants \& redox signaling 2020, 33, 498-516, https://doi.org/10.1089/ars.2019.7905.

70. Ungati, H.; Govindaraj, V.; Narayanan, M.; Mugesh, G. Probing the formation of a seleninic acid in living cells by the fluorescence switching of a glutathione peroxidase mimetic. Angewandte Chemie 2019, 131, 8240-8244, https://doi.org/10.1002/anie.201903958.

71. Chen, B.; Shen, Z.; Wu, D.; Xie, X.; Xu, X.; Lv, L.; Dai, H.; Chen, J.; Gan, X. Glutathione peroxidase 1 promotes NSCLC resistance to cisplatin via ROS-induced activation of PI3K/AKT pathway. BioMed research international 2019, 2019, https://doi.org/10.1155/2019/7640547.

72. Gunawardena, H.P.; Silva, R.; Sivakanesan, R.; Ranasinghe, P.; Katulanda, P. Poor Glycaemic Control Is Associated with Increased Lipid Peroxidation and Glutathione Peroxidase Activity in Type 2 Diabetes Patients. Oxidative medicine and cellular longevity 2019, 2019, https://doi.org/10.1155/2019/9471697.

73. Yi, Z.; Jiang, L.; Zhao, L.; Zhou, M.; Ni, Y.; Yang, Y.; Yang, H.; Yang, L.; Zhang, Q.; Kuang, Y. Glutathione peroxidase 3 (GPX3) suppresses the growth of melanoma cells through reactive oxygen species (ROS)dependent stabilization of hypoxia-inducible factor 1- $\alpha$ and 2- $\alpha$. Journal of cellular biochemistry 2019, 120, 19124-19136, https://doi.org/10.1002/jcb.29240.

74. Zhang, X.; Sui, S.; Wang, L.; Li, H.; Zhang, L.; Xu, S.; Zheng, X. Inhibition of tumor propellant glutathione peroxidase 4 induces ferroptosis in cancer cells and enhances anticancer effect of cisplatin. Journal of cellular physiology 2020, 235, 3425-3437, https://doi.org/10.1002/jcp.29232.

75. Cuevas-González, P.; Liceaga, A.; Aguilar-Toalá, J. Postbiotics and paraprobiotics: From concepts to applications. Food Research International 2020, 109502, https://doi.org/10.1016/j.foodres.2020.109502.

76. Yang, L.-C.; Lin, S.-W.; Li, I.; Chen, Y.-P.; Tzu, S.-Y.; Chou, W.; Chen, C.-C.; Lin, W.-C.; Chen, Y.-L.; Lin, W.-H. Lactobacillus plantarum GKM3 and Lactobacillus paracasei GKS6 Supplementation Ameliorates Bone Loss in Ovariectomized Mice by Promoting Osteoblast Differentiation and Inhibiting Osteoclast Formation. Nutrients 2020, 12, 1914, https://doi.org/10.3390/nu12071914.

77. Vairavel, M.; Devaraj, E.; Shanmugam, R. An eco-friendly synthesis of Enterococcus sp.-mediated gold nanoparticle induces cytotoxicity in human colorectal cancer cells. Environmental Science and Pollution Research 2020, 27, 8166-8175, https://doi.org/10.1007/s11356-019-07511-x.

78. Chuah, L.-O.; Foo, H.L.; Loh, T.C.; Alitheen, N.B.M.; Yeap, S.K.; Mutalib, N.E.A.; Rahim, R.A.; Yusoff, K. Postbiotic metabolites produced by Lactobacillus plantarum strains exert selective cytotoxicity effects on cancer cells. BMC complementary and alternative medicine 2019, 19, 114, https://doi.org/10.1186/s12906019-2528-2.

79. Luang-In, V.; Saengha, W.; Buranrat, B.; Nudmamud-Thanoi, S.; Narbad, A.; Pumriw, S.; Samappito, W. Cytotoxicity of Lactobacillus plantarum KK518 Isolated from Pak-Sian Dong (Thai Fermented Gynandropsis pentaphylla DC.) Against HepG2, MCF-7 and HeLa Cancer Cells. Pharmacognosy Journal 2020, 12, https://doi.org/10.5530/pj.2020.12.148.

80. Pourmollaei, S.; Barzegari, A.; Farshbaf-Khalili, A.; Nouri, M.; Fattahi, A.; Shahnazi, M.; Dittrich, R. Anticancer effect of bacteria on cervical cancer: Molecular aspects and therapeutic implications. Life Sciences 2020, 246, 117413, https://doi.org/10.1016/j.lfs.2020.117413.

81. Chondrou, P.; Karapetsas, A.; Kiousi, D.E.; Vasileiadis, S.; Ypsilantis, P.; Botaitis, S.; Alexopoulos, A.; Plessas, S.; Bezirtzoglou, E.; Galanis, A. Assessment of the Immunomodulatory Properties of the Probiotic Strain Lactobacillus paracasei K5 in vitro and In Vivo. Microorganisms 2020, 8, 709, https://doi.org/10.3390/microorganisms8050709.

82. Nozari, S.; Faridvand, Y.; Etesami, A.; Ahmad Khan Beiki, M.; Miresmaeili Mazrakhondi, S.A.; Abdolalizadeh, J. Potential anticancer effects of cell wall protein fractions from Lactobacillus paracasei on human intestinal Caco-2 cell line. Letters in applied microbiology 2019, 69, 148-154, https://doi.org/10.1111/lam.13198.

83. Bonnet, M.; Buc, E.; Sauvanet, P.; Darcha, C.; Dubois, D.; Pereira, B.; Déchelotte, P.; Bonnet, R.; Pezet, D.; Darfeuille-Michaud, A. Colonization of the human gut by E. coli and colorectal cancer risk. Clinical Cancer Research 2014, 20, 859-867, https://doi.org/10.1158/1078-0432.CCR-13-1343.

84. Fathi-zavoshti, H.; Douroud, N.; Shahbazi, N.; Abbasi, A. Evaluating the Role of Postbiotics as a New Generation of Probiotics in Health and Diseases. Journal of Ardabil University of Medical Sciences 2020, 10, 381-99, https://doi.org/10.29252/jarums.19.4.381.

85. Butt, J.; Epplein, M. Helicobacter pylori and colorectal cancer-A bacterium going abroad? PLoS pathogens 2019, 15, e1007861, https://doi.org/10.1371/journal.ppat.1007861. 
86. Perillo, F.; Amoroso, C.; Strati, F.; Giuffrè, M.R.; Díaz-Basabe, A.; Lattanzi, G.; Facciotti, F. Gut Microbiota Manipulation as a Tool for Colorectal Cancer Management: Recent Advances in Its Use for Therapeutic Purposes. International Journal of Molecular Sciences 2020, 21, 5389, https://doi.org/10.3390/ijms21155389.

87. Rad, A.H.; Aghebati-Maleki, L.; Kafil, H.S.; Gilani, N.; Abbasi, A.; Khani, N. Postbiotics, as Dynamic Biomolecules, and Their Promising Role in Promoting Food Safety. Biointerface Research in Applied Chemistry 2021,11, 14529-44, https://doi.org/10.33263/BRIAC116.1452914544.

88. Konstantinov, S.R.; Kuipers, E.J.; Peppelenbosch, M.P. Functional genomic analyses of the gut microbiota for CRC screening. Nature Reviews Gastroenterology \& Hepatology 2013, 10, 741-745, https://doi.org/10.1038/nrgastro.2013.178.

89. Eslami, M.; Yousefi, B.; Kokhaei, P.; Hemati, M.; Nejad, Z.R.; Arabkari, V.; Namdar, A. Importance of probiotics in the prevention and treatment of colorectal cancer. Journal of cellular physiology 2019, 234, 17127-17143, https://doi.org/10.1002/jcp.28473.

90. Taware, R.; Abnave, P.; Patil, D.; Ramanpillai Rajamohananan, P.; Raja, R.; Soundararajan, G.; Chandra Kundu, G.; Kumar Dhondhiram Kharat, M.; Pai, K.; Ahmad, A. Trichothecin from endophytic fungus Trichothecium sp. and its anticancer effect on murine melanoma and breast cancer cell lines. Current Biochemical Engineering 2015, 2, 73-80, https://doi.org/10.2174/2212711901666140804220845.

91. Saadat, Y.R.; Khosroushahi, A.Y.; Gargari, B.P. A comprehensive review of anticancer, immunomodulatory and health beneficial effects of the lactic acid bacteria exopolysaccharides. Carbohydrate polymers 2019, 217, 79-89, https://doi.org/10.1016/j.carbpol.2019.04.025.

92. Kumar, R.; Bansal, P.; Singh, J.; Dhanda, S. Purification, partial structural characterization and health benefits of exopolysaccharides from potential probiotic Pediococcus acidilactici NCDC 252. Process Biochemistry 2020, 99, 79-86, https://doi.org/10.1016/j.procbio.2020.08.028.

93. Homayouni-rad, A.; Oroojzadeh, P.; Abbasi, A. The Effect of Yeast Kluyveromyces marxianus as a Probiotic on the Microbiological and Sensorial Properties of Set Yoghurt during Refrigerated Storage. Journal of Ardabil University of Medical Sciences. 2021, 10, 254-68, https://doi.org/10.52547/jarums.20.2.254.

94. Almalki, M.A. Exopolysaccharide production by a new Lactobacillus lactis isolated from the fermented milk and its antioxidant properties. Journal of King Saud University-Science 2020, 32, 1272-1277, https://doi.org/10.1016/j.jksus.2019.11.002.

95. Basso, A.; De Castro, R.; De Castro, T.; Guimarães, H.; Polez, V.; Carbonero, E.; Pomin, V.; Hoffmann, C.; Grossi-de-Sa, M.; Tavares, A. Immunomodulatory activity of $\beta$-glucan-containing exopolysaccharides from Auricularia auricular in phagocytes and mice infected with Cryptococcus neoformans. Medical mycology 2020, 58, 227-239, https://doi.org/10.1093/mmy/myz042.

96. Leylabadlo, H.E.; Heravi, F.S.; Soltani, E.; Abbasi, A.; Kafil, H.S.; Parsaei, M.; Sanaie, S.; Ahmadian, Z.; Ghotaslou, R. The role of gut microbiota in the treatment of irritable bowel syndrome. Reviews in Medical Microbiology. 2021, https://doi.org/10.1097/MRM.0000000000000284.

97. Mahdhi, A.; Chakroun, I.; Ruiz, C.E.; Messina, C.M.; Arena, R.; Majdoub, H.; Santulli, A.; Mzoughi, R.; Esteban, M.A. Dietary administration effects of exopolysaccharide from potential probiotic strains on immune and antioxidant status and nutritional value of European sea bass (Dicentrarchus labrax L.). Research in Veterinary Science 2020, https://doi.org/10.1016/j.rvsc.2020.04.008. 